\title{
Antibiotic Resistance Pattern of Escherichia coli Isolated from Diarrhoeic and Non-diarrhoeic Under Five Children in Kano, Nigeria
}

\author{
Nasir Tukur Dabo ${ }^{1}$, Bashir Muhammad ${ }^{2}$, Habeeb Kayode Saka ${ }^{2,3, ~ *, ~}$ \\ Zaharaddin Muhammad Kalgo ${ }^{4}$, Rasaki Adewole Raheem ${ }^{5}$ \\ ${ }^{1}$ Department of Biological Sciences, Bayero University Kano, Kano, Nigeria \\ ${ }^{2}$ Department of Microbiology, Bayero University Kano, Kano, Nigeria \\ ${ }^{3}$ Department of Microbiology, Nigerian Stored Products Research Institute, Kano, Nigeria \\ ${ }^{4}$ Department of Microbiology, Federal University Birnin Kebbi, Kebbi State, Nigeria \\ ${ }^{5}$ Department of Medical Microbiology and Parasitology, University of Ilorin Teaching Hospital, Ilorin, Nigeria
}

Email address:

saka.habeeb@yahoo.com (H. K. Saka)

${ }^{*}$ Corresponding author

\section{To cite this article:}

Nasir Tukur Dabo, Bashir Muhammad, Habeeb Kayode Saka, Zaharaddin Muhammad Kalgo, Rasaki Adewole Raheem. Antibiotic Resistance Pattern of Escherichia coli Isolated from Diarrhoeic and Non-diarrhoeic Under Five Children in Kano, Nigeria. International Journal of Microbiology and Biotechnology. Vol. 4, No. 3, 2019, pp. 94-102. doi: 10.11648/j.jjmb.20190403.15

Received: May 21, 2019; Accepted: June 25, 2019; Published: September 10, 2019

\begin{abstract}
Antibiotic resistance in bacterial pathogens is a global health challenge linked to high morbidity and mortality. This study was carried out among under-five children attending three major hospitals in Kano State namely: Murtala Muhammad Specialists Hospital (MMSH), Wudil General Hospital (WGH) and Bichi General Hospital (BGH), representing the three senatorial districts. Rectal swab specimens from 400 diarrhoeic and 50 non-diarrhoeic children were collected with a sterile transport swab containing Carry-Blair Medium. These were inoculated onto MacConckey and Salmonella-Shigella Agar and incubated at $37^{\circ} \mathrm{C}$ for $18-24$ hours for isolation of bacteria. Bacterial isolates were subjected to battery of biochemical tests (IMViC and KIA) for the identification of Escherichia coli. Antimicrobial susceptibility test (AST) was carried out on E. coli isolated using modified Kirby-Bauer method. The findings revealed $74 \%$ and $66 \%$ E. coli recovery from case and control subjects respectively. The AST revealed trimethoprim-sulfamethoxazole $75.1 \%$ was the most resisted antibiotic, significantly different between the case subjects $(P$-value $=0.031), 83 \%$ were resistant to at least one class of antibiotic, $44.4 \%$ resistant to two classes of antibiotics and significantly higher in the control group $(P$-value $=0.006)$ and $8.0 \%$ MDR rate. Female subjects shows higher resistance to the tested antibiotics but the differences were only significant in amoxicillin-clavulanic acid $(49.6 \%$ versus $32.9 \% ; P$-value $=0.003)$ and trimethoprim-sulfamethoxazole $(91.7 \%$ versus $57.1 \% ; P$-value $=0.037)$ in the case and control group respectively. It can be concluded that $E$. coli is the predominant agent associated with diarrhoea in Kano children and high resistance of trimethoprim-sulfamethoxazole is noteworthy. Hence the need to revise the current diarrhoea treatment regimen for Kano children.
\end{abstract}

Keywords: Escherichia coli, Antibiogram, Diarrhoeic, Resistance, Kano

\section{Introduction}

Antibiotics have accelerated the reduction of infectious disease, saving lives of millions of people in the developed and developing world [1]. Antibiotics have limited the spread of infectious diseases and facilitated the execution of complex medical procedures. While the dependence of modern society on antibiotics has increased, their efficacy is threatened due to naturally occurring process of antimicrobial resistance (AMR). AMR is the resistance developed by microorganism to antimicrobials that was originally effective for treatment of infections caused by those microbes $[2,3]$. AMR in bacterial pathogens is a global health challenge 
linked to high morbidity and mortality [4]. There has been an increase in the incidence of bacteria resistant to multiple antibiotics commonly used in treatment of infections [5]. The magnitude differ between and within a country and different geographic region [6]. Increased antibiotic resistance in pathogens have potentially catastrophic consequences leading to increased morbidity and mortality [5], growing healthcare cost, prolonged hospital stay, as-well as treatment failure for both developing and developed nations [7, 8]. Antibiotic usage play a central role in the emergence of AMR in developing countries as well as worldwide [5]. Bacteria resistance has been identified to pose a challenge to diarrhoea management. Escherichia coli has been identified as the main carrier of antibiotic resistance in a between-species comparison of enteric bacteria isolated from faecal samples [7]. It is increasingly evident that commensal bacteria, animals and environments are reservoir for antibiotic resistance [5], from which pathogenic bacteria can acquire resistance through horizontal gene transfer $[4,8]$. Resistant E. coli are classified by WHO as one of the seven bacteria of international concern [9]. According to the Multiple Indicator Cluster Survey (2018), one in five Kano children die before the age of five years. Diarrhoea was implicated as one of the major causes of mortality among under five Kano children [10]. Diarrhoea is estimated to be a leading cause of underfive death globally [11]. It was reported in 2016 that every 60 seconds a child dies due to diarrhoea [12]. The mortality due to diarrhoea among children younger than five years in Kano was estimated to be $15 \%$ [13], higher than the national average of $9 \%$ [14]. E. coli is a sensitive indicator for the surveillance and spread of antimicrobial resistance among pathogens [5]. The aim of the present study was to determine the socio-demography and clinical characteristics of diarrhoeic and non-diarrhoeic under five children in Kano aswell investigate the resistance pattern of E. coli. There is paucity of information on antibiotic resistance pattern among Kano under five children, this study provides data on the resistance pattern of E. coli, it is envisaged to assist in policy formulation, empirical management and surveillance of resistance among Kano children.

\section{Materials and Methods}

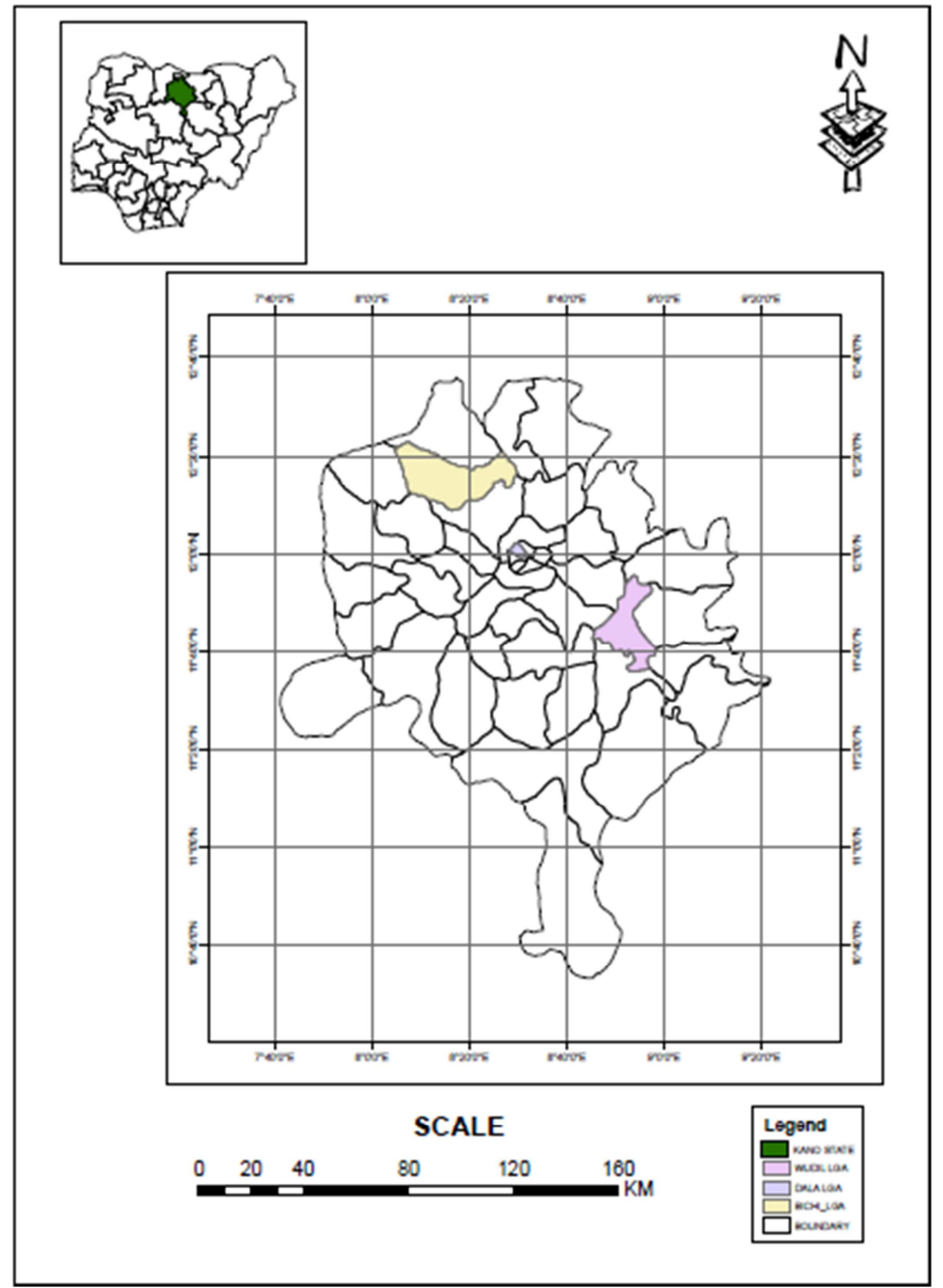

Figure 1. Map of Kano State Showing locations of the Sampling Sites. 
This study was a descriptive cross sectional hospital base study conducted in Kano. Kano is one of the commercial nerve centre of Nigeria located in the Northwest geopolitical zone with $1,818,598$ population of children less than five years (Figure 1). The study was approved by Kano state ministry of health with Ref: MOH/Off/797/T.I/186, verbal and written consent was sought from the parent and guardian of the subjects prior to specimen collection. In this present study rectal swab specimens were obtained from subjects from Bichi General Hospital (BGH), Murtala Muhammad Specialist Hospital (MMSH) and Wudil General Hospital (WGH) in Kano based on the population of each senatorial zones whereby each hospital represents each of the senatorial zones and being the zonal headquarters of each zone. Sample size was calculated using Fisher's formula: $\mathrm{N}=\mathrm{Z}^{2} \mathrm{pq} / \mathrm{d}^{2}$ for population above 10,000 [15]. Using a prevalence of $40.7 \%$ [16], the minimum sample size was calculated as 371 . Thereafter, 400 non repetitive rectal swab specimens were collected from diarrhoeic patients (diarrhoea was described by the passage 3 or more loose or watery stool or at least one bloody stool in a period of 24 hours) based on the population of the three senatorial districts; 174 for MMSH, 123 for WGH and 103 for BGH. In addition, fifty rectal swab specimens were collected from non-diarrhoeic age match as controls. Socio-demographic information and clinical characteristics of the subjects were obtained by survey. Specimens were collected with a sterile transport swab stick containing Carry-Blair medium (Micropoint Diagnostics USA), by inserting the cotton swab stick into the rectum of the subjects and the specimens were transported to microbiology laboratory of AKTH in less than 6 hours of sample collection. The specimens were cultured onto MacConkey (Rapid labs, UK) and then incubated at $37^{\circ} \mathrm{C}$ for $18-24$ hours as described by Procop et al. [17]. All Gram-negative, rod shaped, motile bacterium were subculture onto Eosin Methylene blue agar (EMB) (Rapid labs $U K$ ) and then subjected to a battery of biochemical tests. All Indole positive, Methylred positive, VP negative, Citrate negative Urease negative isolates that produce acid on KIA slants and a green metallic sheen on EMB were identified as species of the genus E. coli as described by Procop et al. [17].

Antimicrobial susceptibility study was carried out using modified Kirby Bauer method as recommended by CLSI [18] in Mueller-Hinton agar (Mast group UK). A panel of 7 antibiotics (All Oxoid $U K$ ) was tested; Cefuroxime sodium (CXM), Cefotaxime (CTX), Amoxicillin Clavulanic acid (AMC), Ceftazidime (CAZ), Ciprofloxacin (CIP), Gentamycin (CN) and Trimethoprim/sulfamethoxazole (SXT). Results were recorded as Resistant (R) and Susceptible (S comprising intermediate) according to the reference zone of inhibition of each antibiotics as contained in CLSI [18]. Resistance to 3 or more classes of antibiotics was regarded as multidrug resistance (MDR). The association between socio-demographic and clinical characteristics as well as resistance to antibiotics was assessed using chi square tests, implemented using SPSS version 20 (IBM, Colorado, $U S A)$. A $P$-value of $<0.05$ was considered indicative of statistically significant differences.

\section{Results}

A total of 400 diarrhoeic subjects were recruited from $\mathrm{BGH}$, MMSH, WGH and 50 non-diarrhoeic subjects in Kano state, distribution of the socio-demography and clinical characteristics of the subjects presented in Table 1. There were $57.2 \%(\mathrm{n}=229)$ male and female $42.8 \%(171)$ in the case subjects, in the control group, $62.0 \%(\mathrm{n}=31)$ male and female $38.0 \%(n=19)$. Children within $0-12$ months age group $43.0 \%$ $(\mathrm{n}=172)$ were the most recruited in the case and children within age group $24-59$ months $38.0 \%(n=19)$ were the most recruited in the control subjects with a significant difference ( $P$-value $=0.003)$ between the groups. The feeding pattern of the subjects were significantly different within the case subjects $(P$-value $=0.005)$, higher proportion of subjects in the case $176(44.0 \%)$ and control 21(42.0\%) subjects. Higher number of subject $38.8 \%$ had diarrhoea $>4$ days before presenting to the hospital, $67.5 \%$ had acute watery diarrhoea. The predominant other clinical symptoms among the case subjects were fever $233(58.3 \%)$ with a statistical difference between the hospital $(P$-value $=0.009)$. From the specimens from 450 subjects investigated, $(329 / 450,73.1 \%) E$. coli were recovered (296/400; $974 \%$ and 33/50; 66\% in case and control respectively). The distribution of $E$. coli isolation according to the socio-demography and clinical characteristics of diarrhoeic and non-diarrhoeic children in Kano state (Table 2), proportion of female was significantly higher within the case subjects $(56.41 \%, P$-value $=0.016)$ and more common in subjects within the age group 0-12months (124/400, 37.6\%). Solids only feeding pattern was significantly more common among the case subjects $(135 / 400,45.60 \%$; $P$-value $=0.005)$. Similarly in the control subjects, solids only feeding pattern was more common $(17 / 33,51.51 \%)$, higher proportion of subjects were from $>24-59$ months age class $(14 / 33,42.42 \%)$ which was statistically different between the age class of the case subjects $(P$-value $=0.003)$. The distribution of antibiotic resistance pattern of $E$. coli isolated from case and control subjects (Table 3 ). A relatively higher rate of resistance to the tested antibiotics were observed among those recovered from children attending BGH (CTX; 13.95\%, AMC; 43.02\%, CIP; $10.46 \%$ and as well as resistance to 2 classes of antibiotics; 45.35\%) and WGH (CAZ; 23.59\%, CN; 6.74\%, SXT; 84.27\% and as well as resistance to a class of antibiotic; $88.76 \%$ ) but significant different only obtained in trimethoprimsulfamethoxazole $(P$-value $=0.031)$. All the $\beta$-lactam antibiotics were significantly different among the case and control subjects except Cefotaxime. A relatively higher resistance rate was observed among the control subjects than the case except for trimethoprim-sulfamethoxazole (75.7\% versus $68.7 \%)$. Resistance to at least two classes of antibiotics was significantly higher in the control subjects than the case subjects $(66.7 \%$ versus $42.0 \%$; $P$-value $=0.006)$. MDR rate of $7.4 \%$ was recorded among the case subjects which was higher among subjects from MMSH (8.3\%). MDR rate of $12.12 \%$ was recorded among the control subjects. 
Antibiotic susceptibility pattern of E. coli in relation to the socio-demography of case and control subjects (Table 4), female subjects in the diarrhoeic group are relatively more resistant to all the tested antibiotics except for gentamycin, but the differences only significant in amoxicillin-clavulanic acid $(49.6 \%$ versus $32.9 \% ; P$-value $=0.003)$. Likewise in the control group, female tends to be more resistant to all the tested antibiotics except to ciprofloxacin and equal resistance to ceftazidime, the difference is only significant in trimethoprimsulfamethoxazole $(91.7 \%$ versus $57.1 \% ; \quad P$-value $=0.037)$. Children within 13-24 months age class in the diarrhoeic group are more resistant to $\beta$-lactam antibiotics; cefuroxime $(18.6 \%)$, amoxicillin-clavulanic acid (44.1\%) and ceftazidime (20.3\%). Significant difference between the diarrhoeic group were observed in trimethoprim-sulfamethoxazole $(P$-value $=0.004)$ and ceftazidime $(P$-value $=0.049)$. Similarly among the control subjects, children within 0-12 months age class are more resistant to the tested antibiotics; cefuroxime (75.0\%), cefotaxime (33.3\%), ceftazidime $(91.7 \%)$, ciprofloxacin $(16.7 \%)$ and trimethoprim-sulfamethoxazole (83.3\%). Children within age class 13-24 months shows a higher resistance to gentamycin $(14.3 \%)$ and children with age $>24$ 59 months shows higher resistance to amoxicillin-clavulanic acid $(85.7 \%)$. The differences in the resistant pattern among the control children was only significant in cefuroxime $(P$ - value $=0.023)$. There was a significant difference between the case and control in amoxicillin-clavulanic acid $(P$ value $=0.000)$, ceftazidime $(P$-value $=0.004)$ and trimethoprimsulfamethoxazole $(P$-value $=0.034)$. Children with diarrhoea that are on mixed feeding pattern (breast milk and solid food) show higher rate of resistance to all $\beta$-lactam antibiotics; cefuroxime $(19.4 \%)$, cefotaxime $(15.5 \%)$, amoxicillinclavulanic acid (42.6\%) and ceftazidime (20.2\%). Children on breast milk only displayed higher resistance to ciprofloxacin (12.5\%), gentamycin (9.4\%) and trimethoprimsulfamethoxazole $(84.4 \%)$. The differences in the resistant pattern among the feeding pattern of children with diarrhoea are only significant in trimethoprim-sulfamethoxazole (Pvalue $=0.004)$. In the non-diarrhoeic group, children on breast feeding only feeding pattern are more resistant to all the tested $\beta$-lactam antibiotics except cefotaxime and children with mixed feeding pattern display higher resistance pattern to ciprofloxacin $(18.2 \%)$, gentamycin $(9.1 \%)$ and trimethoprimsulfamethoxazole $(90.9 \%)$. Significant difference in resistance in relation with feeding pattern of control subjects only observed in cefotaxime $(P$-value $=0.010)$. There was a statistical significant difference between the feeding pattern in the case and control subjects in cefotaxime $(P$-value $=0.001)$ and ceftazidime $(P$-value $=0.045)$.

Table 1. Socio-Demographic and Clinical Characteristics of Diarrhoeic and Non-Diarrhoeic Kano Children under Five Years.

\begin{tabular}{|c|c|c|c|c|c|}
\hline \multirow{2}{*}{ Variable } & \multicolumn{4}{|l|}{ Case } & \multirow{2}{*}{$\begin{array}{l}\text { Control } \\
\text { Control }\left(\mathrm{N}_{\mathrm{c}}=50\right) \text { n }(\%)\end{array}$} \\
\hline & BGH $\left(\mathrm{N}_{\mathrm{b}}=103\right) \mathrm{n}(\%)$ & $\operatorname{MMSH}\left(\mathrm{N}_{\mathrm{m}}=174\right) \mathrm{n}(\%)$ & WGH $\left(N_{w}=123\right)$ n $(\%)$ & Total $\left(N_{d}=400\right) n(\%)$ & \\
\hline \multicolumn{6}{|c|}{ Socio-Demography } \\
\hline \multicolumn{6}{|c|}{ Gender } \\
\hline Female & $39(37.9)$ & $72(41.4)$ & $60(48.8)$ & $171(42.8)$ & $19(38.0)$ \\
\hline Male & $64(62.1)$ & $102(58.6)$ & $63(51.2)$ & $229(57.2)$ & $31(62.0)$ \\
\hline \multicolumn{6}{|l|}{ Age } \\
\hline $0-12$ months & $45(43.7)$ & $64(36.8)$ & $63(51.2)$ & $172(43.0)$ & $18(36.0)^{\#}$ \\
\hline$>24-59$ months & $18(17.5)$ & $38(21.8)$ & $16(13.0)$ & $72(18.0)$ & $19(38.0)$ \\
\hline \multicolumn{6}{|l|}{ Feeding pattern } \\
\hline Solids Only & $45(43.7)$ & $92(52.9)$ & $39(31.7)^{*}$ & $176(44.0)$ & $21(42.0)$ \\
\hline Breast Only & $13(12.6)$ & $27(15.5)$ & $13(10.6)$ & $53(13.3)$ & $10(30.0)$ \\
\hline Mixed & $45(43.7)$ & $55(31.6)$ & $71(57.7)$ & $171(42.8)$ & $19(38.0)$ \\
\hline \multicolumn{6}{|c|}{ Clinical Characteristics } \\
\hline \multicolumn{6}{|c|}{ Onset of Diarrhoea } \\
\hline 3-4 days & $26(25.2)$ & $37(21.3)$ & $27(22.0)$ & $90(22.5)$ & - \\
\hline$>4$ days & $34(33.0)$ & $72(41.4)$ & $49(39.8)$ & $155(38.8)$ & - \\
\hline \multicolumn{6}{|l|}{ Number of stool } \\
\hline $3-4$ & $43(41.7)$ & $85(48.8)$ & $62(50.4)$ & $194(48.5)$ & - \\
\hline $5-6$ & $43(41.7)$ & $49(28.2)$ & $40(32.5)$ & $132(33.0)$ & - \\
\hline$>7$ & $16(15.5)$ & $40(23.0)$ & $21(17.1)$ & $77(19.3)$ & - \\
\hline \multicolumn{6}{|c|}{ Forms of Diarrhoea } \\
\hline Acute Watery & $77(74.8)$ & $108(62.1)$ & $85(69.1)$ & $270(67.5)$ & - \\
\hline Acute Bloody & $14(13.6)$ & $41(23.6)$ & $26(21.1)$ & $81(20.3)$ & - \\
\hline Persistent & $12(11.7)$ & $25(14.4)$ & $12(9.8)$ & $49(12.3)$ & - \\
\hline \multicolumn{6}{|l|}{ Other Symptoms } \\
\hline Fever & $67(65.0)$ & $83(47.7)$ & $83(67.5)^{*}$ & $233(58.3)$ & - \\
\hline Vomiting & $17(16.5)$ & $40(23.0)$ & $12(9.8)$ & $69(17.3)$ & - \\
\hline Dehydration & $3(2.9)$ & $6(3.4)$ & $3(2.4)$ & $12(3.0)$ & - \\
\hline Others & $16(15.5)$ & $45(25.9)$ & $25(20.3)$ & $86(21.5)$ & \\
\hline
\end{tabular}

Key: BGH-Bichi General Hospital, MMSH-Murtala Muhammad Specialist Hospital, WGH-Wudil General Hospital, Number of Stool- Number of Loose/watery stool. $\mathrm{N}_{\mathrm{d}}$-Total Number of Diarrhoeic, children, $\mathrm{N}_{\mathrm{n}}$-Total Number of Non-diarrhoeic children, $\mathrm{N}_{\mathrm{b}}, \mathrm{N}_{\mathrm{m}}$ and $\mathrm{N}_{\mathrm{w}}$-Total Number of children from $\mathrm{BGH}, \mathrm{MMSH}$ and WGH respectively, $\mathrm{n}$-Number obtained, ${ }^{*} \mathrm{P}<0.05$ within case group, Number of stool=Number of stool passed in 24 hours period. 
Nasir Tukur Dabo et al:: Antibiotic Resistance Pattern of Escherichia coli Isolated from Diarrhoeic and Non-diarrhoeic Under Five Children in Kano, Nigeria

Table 2. E. coli Isolation According to Socio-demographic and Clinical Characteristics of Diarrhoeic and Non-diarrhoeic Kano under Five Children.

\begin{tabular}{|c|c|c|c|c|c|}
\hline \multirow{2}{*}{ Variable } & \multicolumn{4}{|c|}{ Case $(\mathrm{N}=296)$} & \multirow{2}{*}{$\begin{array}{l}\text { Control(N=33) } \\
\text { Control n (\%) } \\
\end{array}$} \\
\hline & BGH n (\%) & MMSH n (\%) & WGH n (\%) & Total n(\%) & \\
\hline \multicolumn{6}{|c|}{ Socio-Demography } \\
\hline Gender Female & $32(10.81)$ & $47(15.87)$ & $50(16.89)^{*}$ & $129(43.58)$ & $12(36.36)$ \\
\hline Male & $54(18.24)$ & $74(25.0)$ & 39 (13.17) & $167(56.41)$ & $21(63.63)$ \\
\hline \multicolumn{6}{|l|}{ Age } \\
\hline $0-12$ months & $34(11.48)$ & $43(14.52)$ & $47(15.87)$ & $124(37.6)$ & $12(36.36)^{\#}$ \\
\hline 13-24 months & $36(12.16)$ & $55(18.58)$ & $27(9.12)$ & $118(35.8)$ & $7(21.21)$ \\
\hline$>24-59$ months & $16(4.86)$ & $23(7.77)$ & $15(5.06)$ & $54(16.4)$ & $14(42.42)$ \\
\hline \multicolumn{6}{|l|}{ Feeding pattern } \\
\hline Solids Only & $40(13.5)$ & $66(22.29)$ & $29(8.81)^{*}$ & $135(45.60)$ & $17(51.51)$ \\
\hline Breast Only & $8(2.70)$ & $16(5.40)$ & $8(2.70)$ & $32(10.81)$ & $5(15.15)$ \\
\hline Mixed & $38(12.83)$ & $39(13.17)$ & $52(17.56)$ & $129(43.58)$ & $11(33.33)$ \\
\hline \multicolumn{6}{|c|}{ Clinical Xchritics } \\
\hline \multicolumn{6}{|c|}{ Onset of Diarrhoea } \\
\hline$<24$ hours & $6(2.02)$ & $12(4.05)$ & $11(3.71)$ & $29(9.79)$ & - \\
\hline $1-2$ days & $30(10.13)$ & $34(11.48)$ & $27(9.12)$ & $91(30.74)$ & - \\
\hline 3-4 days & $22(7.43)$ & $27(9.12)$ & $19(6.41)$ & 68 (22.97) & - \\
\hline$>4$ days & $28(9.45)$ & $48(16.21)$ & $32(10.81)$ & $108(36.48)$ & - \\
\hline \multicolumn{6}{|l|}{ Number of stool } \\
\hline $3-4$ & $36(12.16)$ & $60(20.27)$ & $47(15.87)$ & $143(48.31)$ & - \\
\hline $5-6$ & $37(12.50)$ & $31(10.47)$ & $28(9.45)$ & $96(32.43)$ & - \\
\hline$>7$ & $13(4.39)$ & $30(10.13)$ & $14(4.72)$ & $57(19.25)$ & - \\
\hline \multicolumn{6}{|c|}{ Forms of Diarrhoea } \\
\hline Acute Watery & $66(22.29)$ & $74(25.0)$ & $63(21.28)$ & $203(68.58)$ & - \\
\hline Acute Bloody & $10(3.37)$ & $29(9.79)$ & $18(6.08)$ & $57(19.25)$ & - \\
\hline Persistent & $10(3.37)$ & $18(6.08)$ & $8(2.70)$ & $36(12.16)$ & - \\
\hline \multicolumn{6}{|l|}{ Other Symptoms } \\
\hline Fever & $55(18.58)$ & $55(15.58)$ & $61(20.60)^{*}$ & 171(57.77) & - \\
\hline Vomiting & $15(5.06)$ & $30(10.13)$ & $7(2.36)$ & $52(17.56)$ & - \\
\hline Dehydration & $2(0.67)$ & $4(1.35)$ & $2(0.67)$ & $8(2.70)$ & - \\
\hline Others & $14(4.72)$ & $32(10.81)$ & $18(6.08)$ & $61(20.60)$ & - \\
\hline
\end{tabular}

Key: BGH-Bichi General Hospital, MMSH-Murtala Muhammad Specialist Hospital, WGH-Wudil General Hospital, N-Total Number, n-Number obtained, $* \mathrm{P}<0.05$ within individual group, ${ }^{\#} \mathrm{p}<0.05$ between case and control group, Xchritics-Characteristics

Table 3. Antibiotic Resistance Pattern of E. coli Isolated from Diarrhoeic and Non-diarrhoeic Kano Children under Five Years.

\begin{tabular}{|c|c|c|c|c|c|c|}
\hline \multirow[b]{2}{*}{ Antibiotics } & \multicolumn{4}{|c|}{ Case Subjects (N=296) } & \multicolumn{2}{|c|}{ Control Subjects $(\mathrm{N}=33)$} \\
\hline & BGH(N=86) n (\%) & MMSH(N=121) n (\%) & WGH(N=89) n (\%) & Total $_{d}$ n (\%) & Control n (\%) & Total(N=329) n (\%) \\
\hline $\mathrm{CXM}$ & $13(15.12)$ & $22(18.20)$ & $13(14.60)$ & $48(16.21)$ & $15(45.45)$ & $63(19.15)^{\#}$ \\
\hline CTX & $12(13.95)$ & $14(11.57)$ & $12(13.48)$ & $38(12.83)$ & $5(15.15)$ & 43(13.06) \\
\hline CAZ & $9(10.46)$ & $18(14.88)$ & $21(23.59)$ & $48(16.21)$ & $22(66.66)$ & $70(23.64)^{\#}$ \\
\hline AMC & $37(43.02)$ & $51(42.15)$ & $31(34.83)$ & $119(40.20)$ & $26(78.78)$ & $145(44.07)^{\#}$ \\
\hline CIP & $9(10.46)$ & $8(6.61)$ & $5(5.61)$ & $22(7.43)$ & $4(12.12)$ & $26(7.90)$ \\
\hline $\mathrm{CN}$ & $3(3.49)$ & $8(6.61)$ & $6(5.61)$ & $17(5.74)$ & $2(6.06)$ & 19(5.77) \\
\hline SXT & $66(76.74)$ & $83(68.59)$ & 75 (84.27)* & $224(75.67)$ & $23(69.69)$ & $247(75.07)$ \\
\hline Res. to 1 & $72(83.72)$ & $93(76.86)$ & $79(88.76)$ & $244(82.43)$ & $29(87.87)$ & 273(82.97) \\
\hline Res. to 2 & $39(45.35)$ & $50(41.32)$ & $35(39.32)$ & $124(41.89)$ & $22(66.67)$ & $146(44.37)^{\#}$ \\
\hline MDR & $6(6.98)$ & $10(8.26)$ & $6(6.74)$ & $22(7.43)$ & $4(12.12)$ & $26(7.90)$ \\
\hline
\end{tabular}

Key: BGH-Bichi General Hospital, MMSH-Murtala Muhammad Specialist Hospital, WGH-Wudil General Hospital, CXM-Cefuroxime, CAZ-Ceftazidime, AMC- Amoxicillin-clavulanic acid, CIP-Ciprofloxacin, CN-Gentamycin, SXT-Trimethoprim-sulfamethoxazole, ${ }^{*} \mathrm{P}<0.05$ within case group, ${ }^{* *} \mathrm{p}<0.05$ between case and control group, Res. to 1, 2-Resistance to 1 and 2 class of antibiotics, MDR-Multidrug Resistance, ${ }^{*}=\mathrm{P}$-value $<0.05$

Table 4. Antibiotic Resistance Pattern of E. coli in Relation to the Social Demography.

\begin{tabular}{|c|c|c|c|c|c|c|c|c|c|}
\hline \multirow{2}{*}{$\begin{array}{l}\text { Antibiotic } \\
\text { Variable }\end{array}$} & \multicolumn{2}{|c|}{$\begin{array}{l}\text { Case } \\
\text { Control }\end{array}$} & \multirow{2}{*}{$\begin{array}{l}\text { CXM n (\%) } \\
\text { Case Control } \\
\end{array}$} & \multirow{2}{*}{$\begin{array}{l}\text { CTX n (\%) } \\
\text { Case Control } \\
\end{array}$} & \multirow{2}{*}{$\begin{array}{l}\text { AMC n (\%) } \\
\text { Case Control }\end{array}$} & \multirow{2}{*}{$\begin{array}{l}\text { CAZ n (\%) } \\
\text { Case Control }\end{array}$} & \multirow{2}{*}{$\begin{array}{l}\text { CIP n (\%) } \\
\text { Case Control } \\
\end{array}$} & \multirow{2}{*}{$\begin{array}{l}\text { CN n (\%) } \\
\text { Case Control }\end{array}$} & \multirow{2}{*}{$\begin{array}{l}\text { SXT n (\%) } \\
\text { Case Control }\end{array}$} \\
\hline & $\mathbf{N}$ & $\mathbf{N}$ & & & & & & & \\
\hline \multicolumn{10}{|l|}{ Gender } \\
\hline Female & 129 & 12 & $23(17.8) 6(50.0)$ & $20(15.5) 3(25.0)$ & $64(49.6) * 10(83.3)$ & $25(19.4) 8(66.7)$ & $11(8.5) 1(8.3)$ & $7(5.4) 1(8.3)$ & $100(77.5) 11(91.7)^{*}$ \\
\hline Male & 167 & 21 & $25(15.0) 9(42.9)$ & $18(10.8) 2(9.5)$ & $55(32.9) 16(76.2)$ & $23(13.8) 14(66.7)$ & $11(6.6) 3(14.3)$ & $10(6.0) 1(4.8)$ & $124(74.3) 12(57.1)$ \\
\hline \multicolumn{10}{|l|}{ Age } \\
\hline $0-12 \mathrm{M}$ & 124 & 12 & $20(16.1) 9(75.0)^{*}$ & $19(15.3) 4(33.3)$ & $53(42.7) 9(75.0)^{\#}$ & $21(16.9)^{*} 11(91.7)^{\#}$ & $10(8.1) 2(16.7)$ & $8(6.5) 1(8.3)$ & $104(83.9) * 10(83.3)^{*}$ \\
\hline $13-24 \mathrm{M}$ & 118 & 7 & $22(18.6) 3(42.9)$ & $16(13.6) 1(14.3)$ & $52(44.1) 5(71.4)$ & $24(20.3) 4(57.1)$ & $8(6.8) 1(14.3)$ & $6(5.1) 1(14.3)$ & $87(73.7) 5(71.4)$ \\
\hline$>24-59 \mathrm{M}$ & 54 & 14 & $6(11.1) 3(21.4)$ & $3(5.6) 0(0.0)$ & $14(25.9) 12(85.7)$ & $3(5.6) 7(50.0)$ & $4(7.4) 1(7.1)$ & $3(5.6) 0(0.0)$ & $33(61.1) 8(57.1)$ \\
\hline Feeding $\mathrm{P}$ & & & & & & & & & \\
\hline
\end{tabular}




\begin{tabular}{llllllllll}
\hline Antibiotic & $\begin{array}{l}\text { Case } \\
\text { Control }\end{array}$ & CXM n (\%) & CTX n (\%) & AMC n (\%) & CAZ n (\%) & CIP n (\%) & CN n (\%) & SXT n (\%) \\
\hline Variable & $\mathbf{N}$ & $\mathbf{N}$ & Case Control & Case Control & Case Control & Case Control & Case Control & Case Control & Case Control \\
\hline $\begin{array}{l}\text { Solids } \\
\text { only }\end{array}$ & 135 & 17 & $19(14.1) 6(35.3)$ & $16(11.9) 1(5.9)^{\#}$ & $51(37.8) 14(82.4)$ & $20(14.8) 9(52.9)^{\#}$ & $8(5.9) 2(11.8)$ & $6(4.4) 1(5.9)$ & $92(68.1)^{*} 10(58.8)$ \\
$\begin{array}{l}\text { Breast } \\
\text { only }\end{array}$ & 32 & 5 & $4(12.5) 4(80.0)$ & $2(6.3) 3(60.0)^{*}$ & $13(40.6) 3(60.0)$ & $2(6.2) 5(100.0)$ & $4(12.5) 0(0.0)$ & $3(9.4) 0(0.0)$ & $27(84.4) 3(60.0)$ \\
Mixed & 129 & 11 & $25(19.4) 5(45.5)$ & $20(15.5) 1(9.1)$ & $55(42.6) 9(81.8)$ & $26(20.2) 8(72.7)$ & $10(7.8) 2(18.2)$ & $8(6.2) 1(9.1)$ & $105(81.4) 10(90.9)$ \\
\hline
\end{tabular}

Key: CXM-Cefuroxime, CAZ-Ceftazidime, AMC- Amoxicillin-clavulanic acid, CIP-Ciprofloxacin, CN-Gentamycin, SXT-Trimethoprim-sulfamethoxazole, $* \mathrm{P}<0.05$ within individual group, $\# \mathrm{p}<0.05$ between case and control group, M-Month, P-Pattern.

\section{Discussion}

Diarrhoea is one of the most common illness and cause of death in young children in Kano and Nigeria [10]. AMR has become one of the world's most pressing public health challenge of this era. Unnecessary use of antibiotics without prescription for treatment of common bacterial infections is considered as one of the leading causes of the emergence of antibiotic resistance in common pathogens like E. coli.

The socio-demography and clinical characteristics of the children shows that $(42.8 \% \mathrm{n}=171)$ were females $(57.3 \%$, $\mathrm{n}=229)$ were males, these findings were similar to the study of Tian et al. [19] (58.1\% male and 41.9\% female), Haghi et al. [20] (60.7\% male and 39.3\% female) and Natarajan et al. [21] (63\% males and 37\% female) who had more male subjects than female. However, this observation is at variance with the study of Farfan-Garcia et al. [22], Ifeanyi et al. [23] and Shamki et al. [23] with $55.6 \%, 55.0 \%$ and $51.3 \%$ female dominance in their respective reports. The reason for higher number of male subjects cannot be established but Kano Multiple Indicator Cluster Survey (KMICS, 2018) reported that diarrhoea are more common in male than female children in Kano [10]. The relative higher proportion of the subjects falling within the age group 0-12 months $(43.0 \%$, $\mathrm{n}=172$ ) is in agreement with the study of Farfan-Garcia et al. [22], Tian et al. [19] and Shamki et al. [24], with higher number of subjects from age group 0-12 months. Age group below 12 months had already been established as a potential risk factor for diarrhoea in children [25]. This is at variance with KMICS (2018) with 13-24 months age group having more diarrhoea. However, Haghi et al. [20] had more subjects in age group $>24-59$ months.

Most of the subjects had solids only feeding pattern $(44.0 \%, \mathrm{n}=176)$ in the case subjects, which is similar to the study of Al-Yassari et al. [26], with higher number of subjects with artificial feeding pattern. Diarrhoea onset before reporting to the medical facility shows that most subjects $(38.8 \%, \mathrm{n}=155)$ report to the facility in $>4$ days of passing loose/watery stool, delayed care seeking maybe as a result of the financial status of the parent or distance of their home to the hospital facility, however, it might be as a result of distrust of healthcare services [27] or personal medication and herbal treatment at home before reporting to the medical facility. Most of the subjects had 3-4 loose/watery stool in 24 hours period $(48.5 \%, n=194)$ with greater proportion of subjects with acute watery diarrhoea $270(67.5 \%)$ which is in agreement with a similar study in Abuja, Nigeria by Ifeanyi et al. [23] with higher number of children with acute watery diarrhoea which may be due to the quality of water used at home.

In addition to the clinical state of diarrhoea among the subjects, other clinical symptoms that was predominant among the subjects was fever which accounts for $58.3 \%(n=233)$, similar to findings of KMICS (2018) with report of high rate of fever among Kano under five children. This present study revealed the overall prevalence of $E$. coli was $74 \%$ $(n=296 / 400)$ in the diarrhoeic group and 66\% $(n=33 / 50)$ proportion was recorded in the non-diarrhoeic group is similar to what was observed in previous study in Kano [16]. The high rate of isolation of $E$. coli from both subjects may be due to the fact that $E$. coli colonizes the gastrointestinal tract of infants' immediately after birth and coexist in good health with man for a mutual benefits [28]. The emergence and spread of AMR has become a major global public health concern [29], the antibiotic susceptibility pattern of $E$. coli from this study shows that $83.0 \%(\mathrm{n}=273 / 329)$ of $E$. coli from this study were resistant to at least one class of antibiotics, similar to the finding of Singh et al. [5]. The resistance to even a single antibiotic is a cause for concern as it highlights the problem of antibiotic resistance prevalence and the potential reservoir of genes available to pathogens for developing antibiotic resistance. MDR rate of $7.9 \%(26 / 329)$ in this study is at variance with the study of Seidman et al. [7] with $32 \%$ MDR rate. The MDR in E. coli isolates in this study area possibly reflects the spread and emergence of the antibiotic resistance gene pool in general, which may be higher in incidence when wider panels of antibiotics are investigated. Highest resistance was observed in trimethoprim-sulfamethoxazole $(75.7 \%$ in case subjects and $69.7 \%$ in control subjects), is higher than what was reported by Abdullahi et al. [16] among E. coli isolates from Kano children. The high resistance to trimethoprim-sulfamethoxazole may be due to the indiscriminate use as one of the first line drug in diarrhoea management, which is in agreement with the findings of Ochoa et al. [30] they reported 79\% resistance to trimethoprim sulfamethoxazole, $73.7 \%$ resistance reported from infant by Dhaka et al. [31]. However Putnam et al. [32] reported 42.5\% resistance to trimethoprim-sulfamethoxazole, Shakya et al. [33] reported 29\% resistance to trimethoprimsulfamethoxazole, and a much higher resistance pattern (82\%) to trimethoprim-sulfamethoxazole was reported by Al-Yassari et al. [26] and $97.6 \%$ resistance to trimethoprimsulfamethoxazole reported by Shah et al. [34]. Ochoa et al. [30] reported that a higher resistance to trimethoprim- 
sulfamethoxazole was exhibited by $E$. coli from case subjects than the control subjects. Over $40 \%$ of the $E$. coli isolated from subjects were resistant to trimethoprim-sulfamethoxazole and AMC, this could be attributable to user related factors such as self-medication, non-compliance, advertising pressures due to popularity of a particular drug like Augmentin and Septrin (trimethoprim-sulfamethoxazole) which is like a household name in Nigeria. Further to those mentioned, health care givers not carrying out antimicrobial susceptibility testing before antibiotics prescription (maybe due to lack of facility or the understanding of the financial status of the patients) or mothers who bring children to health centres might seek antibiotics not just for the episode of illness, but stockpile the extra antibiotic for that occasion when reaching the clinic might not be so easy due to distance or long queue in hospitals, a survival strategy where access is limited which is common in developing countries. In some cases, friends and families give unexhausted antibiotics to their sick relatives most especially children without understanding the nature of ailment. Resistance to trimethoprim-sulfamethoxazole has been linked to increased resistance to sulphur-potentiated antimicrobials.

The resistance to ciprofloxacin in this study was $7.9 \%$, similar to the findings of Odetoyin et al. [35], they reported $7.2 \%$ resistance to ciprofloxacin, at variance with the study of Shah et al. [34] with $4.8 \%$ resistance and Dhaka et al. [31], reported $68.4 \%$ ciprofloxacin resistance. The least resistance was observed in gentamycin which might be due to the fact that gentamycin is not tolerated through the oral route and may likely be less abused (5.7\% resistance in case subjects and $6.1 \%$ resistance in control subjects) which is at variance with the findings of Al-Yassari et al. [26] who reported 51.3\% resistance to gentamycin. The variation in the resistance pattern might be due to differences in antibiotic policy. Higher susceptibility to ciprofloxacin was observed (over 90\% susceptibility) but fluoroquinolones are not approved for children because of the immature joints which might pose a damage risk. There is neither a defined position on the effect of age of children on its antibiotic susceptibility pattern to antibiotics nor a defined position on the role of gender. In this study, female population tends to be more resistant to the tested antibiotics with a higher significance rate within age class 13-24 months. Shakya et al. [33] found higher resistance among female children than male although the study didn't correlate with age class. Furthermore, E. coli bearing transferable R plasmids was more often found to be associated with antibiotic resistance among female than male in a study conducted among children in Greece [36]. However, Sahoo et al. [37] found higher antibiotics resistance among male subjects. Singh et al. [5] reported equal resistance rate among male and female. Male subjects in the non-diarrhoeic group tends to be more resistant to the tested antibiotics with no significant difference within the age class of subjects.

\section{Conclusion}

This study revealed that $E$. coli was the predominant isolate which was higher among 0-12 months age group.
There was a higher resistance among E. coli recovered from female subjects as well as children attending BGH and WGH. Though gentamycin and ciprofloxacin presents better effects on the isolates, however cefotaxime with relatively close effects is better recommended for the treatment of diarrhea due to the side effects of fluoroquinolones in children and gentamycin not tolerated orally. Hence the need to revise the current diarrhoea treatment regimen for Kano children and smart policy on antibiotics use to address unnecessary prescription of broad spectrum antibiotics prescribed by physicians and other health practitioner to curb the menace of drug resistant strains in the population.

\section{Authors Contribution}

SKH, NTD and MB conceive and design the study, SKH collected the samples and performed the laboratory analysis. SKH analysed the data assisted by RRA and ZMK, SKH wrote the manuscript, assisted by NTD. All authors revised the manuscript before final submission.

\section{Acknowledgements}

We would like to appreciate the support of the technical head of Microbiology and Parasitology Mallam Nasiru Magaji, Nasiru Dogua and Usman Bichi.

\section{References}

[1] Araya, P., Hug, J., Joy, G., Oschmann, F. and Rubinstein, S. The Impact of Water and Sanitation on Diarrhoeal Disease Burden and Over-Prescription of Antibiotics. Presented to the Review on Antimicrobial Resistance. Master of Public Administration, London School of Economics and Political Science, London. (2016)

[2] WHO (2015). Antimicrobial resistance. Available at: $\mathrm{http}: / /$ www.who.int/mediacentre/factsheets/fs 194/en/ [Accessed November 24, 2018]

[3] Davies, J and Davies, D. Origins and Evolution of Antibiotic Resistance. Microbiology and Molecular Biology Reviews, 2010; 74 (3): 417-433. 1092-2172/10/\$12.00 doi: 10.1128/MMBR.00016-10.

[4] Frieri, M., Kumar, K. and Boutin, A. Antibiotic Resistance. Journal of Infection and Public Health, 2017; 10: 369-378. http://dx.doi.org/10.1016/j.jiph.2016.08.007

[5] Singh, A. K., Das, S., Singh, S., Gajamer, V. R., Pradhan, N., Lepcha, Y. D., et al. Prevalence of antibiotic resistance in commensal Escherichia coli among the children in rural hill communities of Northeast India. PLoS ONE, 2018; 13 (6): e0199179.

https://doi.org/10.1371/journal.pone.0199179

[6] Abrar, S., Hussain, S., Khan, R. A., Ain, N. U., Haider, H. and Riaz, S. Prevalence of Extended-spectrum- $\beta$-lactamase-Producing Enterobacteriaceae: First Systematic Meta-Analysis Report from Pakistan. Antimicrobial Resistance and Infection Control, 2018; 7 (26): 1-11. https://doi.org/10.1186/s13756-018-0309-1 
[7] Seidman, J. C., Anitha, K. P., Kanungo, R., Bourgeois, A. L. and Coles C. L. Risk Factors for Antibiotic-Resistant E. coli in Children in a Rural Area. Epidemiology of Infections, 2009; 137 (6): 879-888. doi: 10.1017/S0950268808001519

[8] Prigitano, A., Romanò, L., Auxilia, F., Castaldi, S. and Tortorano, A. M. Antibiotic Resistance: Italian Awareness Survey. Journal of Infection and Public Health, 2016; 11: 30 34. https://doi.org/10.1016/j.jiph.2017.02.010

[9] Chaudhary, A. S. A review of Global Initiatives to Fight Antibiotic Resistance and Recent Antibiotics' Discovery. Acta Pharmaceutica Sinica B. 2016; 6 (6): 552-556

[10] National Bureau of Statistics (NBS), Kano State Bureau of Statistics (KBS) and United Nations Children's Fund (UNICEF). Multiple Indicator Cluster Survey 2016-17, Final Report. Kano, Nigeria: National Bureau of Statistics and United Nations Children's Fund, 2018

[11] Seidman, J. C., Johnson, L. B., Levens, J., Mkocha, H., Muñoz, B., Silbergeld, E. K., West, S. K. et al. Longitudinal Comparison of Antibiotic Resistance in Diarrheagenic and Non-pathogenic Escherichia coli from Young Tanzanian Children. Frontiers in Microbiology, 2016; 7: 1420. doi: $10.3389 /$ fmicb.2016.01420

[12] UNICEF. One is Too Many: Ending Child Deaths from Pneumonia and Diarrhoea. 2016. Available at: https://www.unicef.org/publications/index_93020.html [Accessed on $20^{\text {th }}$ February, 2019]

[13] Ginginyu, I. M. 1 in 5 Kano Kids Dies Before Age 5- Survey. 2016. DailyTrust Newspaper [Online]. $18^{\text {th }}$ August. Available on:

http://www.dailytrust.com.ng/news/general/story/159378.html [Accessed 27 ${ }^{\text {th }}$ September, 2016]

[14] Anwar, A. (2016). Kano Leads in under 5 Mortality Rate. The Guardian Newspaper [Online]. $3^{\text {rd }}$ April 2016. Available at> guardian.ng/news/kano-leads-in-under-5-mortality-rate/ [Accessed $27^{\text {th }}$ September, 2016]

[15] Charan, J. and Biswas, T. How to Calculate Sample Size for Different Study Designs in Medical Research? Indian Journal of Psychological Medicine, 2013; 35 (2): 121-126

[16] Abdullahi, M., Olonitola, S. O., and Inabo, I. H. Isolation of Bacteria Associated with Diarrhoea among Children Attending some Hospitals in Kano Metropolis, Kano State, Nigeria. Bayero Journal of Pure and Applied Sciences, 2010;3 (1): $10-15$

[17] Procop, G. W., Church, D. L., Hall, G. S., Janda, W. M., Koneman, E. W., Schreckenberger, P. C. and Woods, G. L. Koneman's Color Atlas and Textbook of Diagnostic Microbiology, $7^{\text {th }}$ Edition, Wolters Kluwer, 2017

[18] Clinical and Laboratory Standards Institute (CLSI). (2017). Performance Standards for Antimicrobial-Susceptibility Testing. Informational Supplement. 27th Edition, M 100, Wayne, Pannsylvannia, 34 (1): 1-230

[19] Tian, L., Zhu, X., Chen, Z., Liu, W., Li, S., Yu, W. et al. Characteristics of Bacterial Pathogens Associated with Acute Diarrhea in Children under 5 Years of Age: A Hospital-Based Cross-Sectional Study. BMC Infectious Diseases, 2016; 16 (253): 1-8 DOI 10.1186/s12879-016-1603-2

[20] Haghi, F., Zeighami, H., Hajiahmadi, F., Khoshvaght, H. and Bayat, M. Frequency and Antimicrobial Resistance of
Diarrhoeagenic Escherichia coli from Young Children in Iran. Journal of Medical Microbiology, 2014; 63: 427-432. DOI 10.1099/jmm.0.064600-0

[21] Natarajan, M., Kumar, D., Mandal, J., Biswal, N. and Stephen, S. A study of virulence and antimicrobial resistance pattern in diarrhoeagenic Escherichia coli isolated from diarrhoeal stool specimens from children and adults in a tertiary hospital, Puducherry, India. Journal of Health, Population and Nutrition, 2018; 37:17. https://doi.org/10.1186/s41043-018-0147-z

[22] Farfán-García, A. E., Zhang, C., Imdad, A., Arias-Guerrero, M. Y., Sánchez-Alvarez, N. T., Shah, R. et al. Case-Control Pilot Study on Acute Diarrheal Disease in a Geographically Defined Pediatric Population in a Middle Income Country, Hindawim International Journal of Pediatrics, 2017. Article ID 6357597. https://doi.org/10.1155/2017/6357597

[23] Ifeanyi, C. I. C., Ikeneche, N. F., Bassey, B. E., Al-Gallas, N., Aissa, R. B. and Boudabous, A. Diarrheagenic Escherichia coli pathotypes isolated from children with diarrhea in the Federal Capital Territory Abuja, Nigeria. Journal of Infection in Developing Countries, 2015; 9: 165-174. doi: $10.3855 /$ jidc. 5582

[24] Shamki, J. A., Al-Charrakh, A. H. and Al-Khafaji, J. K. Detection of ESBLs in Enteropathogenic E. coli (EPEC) Isolates Associated with Infantile Diarrhea in Kut City. Medical Journal of Babylon, 2012; 9 (2).

[25] Gupta, A., Sarker, G., Rout, A. J., Mondal, T. and Pal, R. (2015). Risk Correlates of Diarrhea in Children under 5 Years of Age in Slums of Bankura, West Bengal. Journal of Global Infectious Disease, 7: 23-9. DOI: 10.4103/0974-777X.150887.

[26] Al-Yassari, A. S. S., Al-Dahmoshi, H. O., Al-Saad, N. F., AlDabagh, N. N., Al-Khafaji, N. S., Mahdi, R. K. et al. Occurrence of AMPC, MBL, CRE and ESBLs among Diarrhegenic E. coli Recovered from Infantile Diarrhea, Iraq. International Journal of Micro Biology, Genetics and Monocular Biology Research, 2016; 2 (2): 21-29

[27] Tickell, K. D., Pavlinac, P. B., John-Stewart, G. C. Denno, D. M., Richardson, B. A., Naulikha, J. M. et al. Impact of Childhood Nutritional Status on Pathogen Prevalence and Severity of Acute Diarrhea. American. Journal of Tropical Medicine and Hygiene, 2017; 97 (5): 1337-1344. doi: 10.4269/ajtmh.17-0139

[28] Kaper, J. B., Nataro, J. P. and Mobley, H. L. Pathogenic Escherichia coli. Nature Review in Microbiology, 2004; 2: 123-140. doi: 10.1038/nrmicro818

[29] Bai, L., Wang, L., Yang, X. Wang, J., Gan, X., Wang, W. et al. Prevalence and Molecular Characteristics of ExtendedSpectrum $\beta$-Lactamase Genes in Escherichia coli Isolated from Diarrheic Patients in China. Frontiers in. Microbiology, 2017; 8: 144. doi: 10.3389/fmicb.2017.00144

[30] Ochoa, T. J., Ruiz, J., Molina, M., Del Valle, L. J., Vargas, M., Gil, A. I. et al. High Frequency of Antimicrobial Drug Resistance of Diarrheagenic Escherichia coli in Infants in Peru. American Journal of Tropical Medicine and Hygiene, 2009; 81 (2): 296-301

[31] Dhaka, P., Vijay, D., Vergis, J., Negi, M., Kumar, M., Mohanet, V. al. Genetic Diversity and Antibiogram Profile of Diarrhoeagenic Escherichia coli Pathotypes Isolated from Human, Animal, Foods and Associated Environmental Sources. Infection Ecology and Epidemiology, 2016; 6: 31055 - http://dx.doi.org/10.3402/iee.v6.31055 
[32] Putnam, S. R. Riddle, M. S., Wierzba, T. F. Pittner, B. T., Elyazeed, R. A., El-Gendy, A. et al. Antimicrobial Susceptibility Trends among Escherichia coli and Shigella spp. Isolated from Rural Egyptian Paediatric Populations with Diarrhoea between 1995 and 2000. Clinical Microbiology Infections, 2004;10: 804-810. doi: 10.1111/j.14690691.2004.00927.x

[33] Shakya, P., Barrett, P., Diwan, V., Marothi, Y., Shah, H., Chhari, N. et al. Antibiotic Resistance among Escherichia coli Isolates from Stool Samples of Children Aged 3 to 14 Years from Ujjain, India. BMC Infectious Diseases, 2013; 13: 477 http://www.biomedcentral.com/1471-2334/13/477

[34] Shah, M., Kathiiko, C., Wada, A. Odoyo, E., Bundi, M., Miringu, G. et al. Prevalence, Seasonal Variation, and Antibiotic Resistance Pattern of Enteric Bacterial Pathogens among Hospitalized Diarrheic Children in Suburban Regions of Central Kenya. Tropical Medicine and Health, 2016; 44: 39. DOI 10.1186/s41182-016-0038-1
[35] Odetoyin, B. W. Hofmann, J., Aboderin, A. O. and Okeke, I. N. Diarrhoeagenic Escherichia coli in mother child Pairs in Ile-Ife, South Western Nigeria. BMC Infectious Diseases, 2016; 16:28. DOI 10.1186/s12879-016-1365-x

[36] Vatopoulos, A. C., Varvaresou, E., Petridou, E., Moustaki, M., Kyriakopoulos, M., Kapogiannis, D., et al. High Rates of Antibiotic Resistance among Normal Fecal Flora Escherichia coli Isolates in Children from Greece. Clinical Microbiology Infections, 1998; 4: 563-569

[37] Sahoo, K. S., Tamhankar, A. J., Sahoo, S., Sahu, P. S., Klintz, S. R. and Lundborg, C. S. Geographical Variation in Antibiotic-Resistant Escherichia coli Isolates from Stool, Cow-Dung and Drinking Water. International Journal of Environmental Resource in Public Health, 2012; 9: 746-759; doi: 10.3390/ijerph9030746 